\title{
Use of Schizosaccharomyces strains for wine fermentation-Effect on the wine composition and food safety
}

\author{
A.E. Mylona, J.M. Del Fresno, F. Palomero, I. Loira, M.A. Bañuelos, A. Morata, F. \\ Calderón, S. Benito , J . A. S u á r e z - L e p e
}

\begin{abstract}
A B S T R A C T
Schizosaccharomyces was initially considered as a spoilage yeast because of the production of undesirable metabolites such as acetic acid, hydrogen sulfide, or acetaldehyde, but it currently seems to be of great value in enology.o ced Nevertheless, Schizosaccharomyces can reduce all of the malic acid in must, leading to malolactic fermentation. Malolactic fermentation is a highly complicated process in enology and leads to a higher concentration of biogenic amines, so the use of Schizosaccharomyces pombe can be an excellent tool for assuring wine safety. Schizosaccharomyces also has much more potential than only reducing the malic acid content, such as increasing the level of pyruvic acid and thus the vinylphenolic pyranoanthocyanin content. Until now, few commercial strains have been available and little research on the selection of appropriate yeast strains with such potential has been conducted. In this study, selected and wild Sc. pombe strains were used along with a Saccharomyces cerevisiae strain to ferment red grape must. The results showed significant differences in several parameters including non-volatile and volatile compounds, anthocyanins, biogenic amines and sensory parameters.
\end{abstract}

\section{Introduction}

The world wine market is experiencing increasing interest in new yeast strains that can produce unique wines with novel properties (Benito et al., 2015a; Carrau et al., 2015; Englezos et al., 2015; Esteve-Zarzoso et al., 1998; Fleet, 2008; Jolly et al., 2014, 2006; Medina et al., 2013; Pretorius, 2000; Uthurry et al., 2004). This is the reason that certain non-Saccharomyces yeast, such as Schizosaccharomyces, which have the ability to lower the malic acid content of wine, could prove to be an excellent alternative to lactic acid bacteria and are currently viewed with much interest (Benito et al., 2015b, 2014a; Fleet, 1999; Suárez-Lepe et al., 2012).

Schizosaccharomyces was initially considered as a spoilage yeast because of the production of undesirable metabolites that produced a negative sensory impact, but it has been used successfully at an industrial level in cane sugar fermentation during rum making, palm wine production and cocoa fermentation (Fleet, 1999), so there are high hopes for its use in the wine-making industry (Suárez-Lepe et al., 2012). Malolactic fermentation performed by Oenococcus oeni is usually used to reduce the malic acid content of musts and wines, mostly in red winemaking. However, malolactic fermentation is sometimes a highly complicated process in enology because of the growth requirements of the bacteria employed (Terrade and Mira de Orduña, 2009). The possible use of maloalcoholic fermentation could be an excellent way to preserve young aroma characteristics while reducing the harsh "green apple sourness" attributed to malic acid. It is evident that the use of Sc. pombe could become an invaluable new tool for grapes from the northern viticultural regions, where malic acid is present in excessive concentrations. Although the International Organization of Vine and Wine (OIV) approved "Deacidification by Schizosaccharomyces" (OIV, 2013), few commercial strains are available (Benito et al., 2014b; Suárez-Lepe et al., 2012) as a consequence of its high acetic acid production rate of approximately $1 \mathrm{~g} / \mathrm{L}$ (Benito et al., 2012, 2014b). A high acetic acid content is inconsistent with quality wine. Mixed and sequential cultures with Saccharomyces have been used to reduce the negative effects of the currently available Sc. spp. strains (Benito et al., 2012, 2014c). The selection of more appropriate Sc. strains is therefore of great enological interest.

Nevertheless, Sc. pombe has much greater potential than just its ability to lower the malic acid content and ferment sugar. Some researchers are using Sc. pombe to lower gluconic acid (Peinado et al., 2004a, 2004b, $2005,2007)$. Another application is aging over lees because of the stronger autolytic release of polysaccharides than with Saccharomyces (Palomero et al., 2009). The ability of Sc. pombe to reduce 4-ethylphenol in wine due to its high adsorption ability has also been studied (Palomero et al., 2011). Furthermore the urease activity (Deák, 2008; Lubbers et al., 1996) is also of much interest concerning food safety. Urea is the primary precursor of ethyl carbamate (Uthurry et al., 2004) so reducing the urea content could lower ethyl carbamate, which is one of the principal food safety problems 
in modern enology (Benito, 2015c; Uthurry et al., 2006). Additionally, the use of Schizosaccharomyces could limit the risk of biogenic amines (Alcaide-Hidalgo et al., 2007; Benito, 2015c), which are notorious for causing physiological problems in humans (MorenoArribas and Polo, 2008). Moreover, Schizosaccharomyces produces a high quantity of pyruvic acid (Benito et al., 2014a), and the significant hydroxycinnamate decarboxylase activity of Schizosaccharomyces favors the formation of vinylphenolic pyranoanthocyanins (Morata et al., 2012).

The aim of this study was to identify suitable Sc. pombe strains for winemaking that enhance wine quality and food safety by studying their performance in red must fermentation.

\section{Materials and methods}

\subsection{Microorganisms}

The yeast used in this study were the wild Schizosaccharomyces pombe strains 2139 and 938 from the type collection of the Institute for Industrial Fermentations (IFI, CSIC, Madrid, Spain) as well as V1 and 4.2, which were selected for their low production of volatile acids (Benito et al., 2014b). The Saccharomyces cerevisiae strain selected was 7VA from the "Laboratorio de Tecnología de Alimentos" of E.T.S.I. Agronomos in the Madrid collection because of its high pyruvic acid and acetaldehyde production (Morata et al., 2006). The lactic acid bacterial strain used was O. oeni 217 (Spanish Type Culture Collection, Valencia, Spain) and was selected for its good deacidification properties and its high resistance to low $\mathrm{pH}$.

\subsection{Vinification}

All fermentations were undertaken using must from Vitis vinifera $\mathrm{L}$. cultivar Tempranillo grapes grown at Socuéllamos, Ciudad Real in Castilla la Mancha, Spain. The must was pasteurized in an autoclave for $1 \mathrm{~min}$ at $105^{\circ} \mathrm{C}$ in $24-\mathrm{L}$ tanks. Sugars were amended up to $207 \mathrm{~g} / \mathrm{L}$ and malic acid up to $4.87 \mathrm{~g} / \mathrm{L}$, and the final $\mathrm{pH}$ was 3.14. Citric acid was $0.24 \mathrm{~g} / \mathrm{L}$, and lactic and acetic acids were less than $0.1 \mathrm{~g} / \mathrm{L}$. To facilitate the fermentation, nutrients were added at a concentration of $0.4 \mathrm{~g} / \mathrm{L}$ (Nutrient Vit-Lallemand, Montreal, Canada). Six experiments were performed in triplicate: (i) inoculation of the must with Sc. Pombe 2139, (ii) inoculation of the must with Sc. Pombe 938, (iii) inoculation of the must with Sc. pombe V1, (iv) inoculation of the must with Sc. Pombe 4.2, (v) inoculation of the must with S. cerevisiae 7VA, and (vi) inoculation of the must with S. cerevisiae 7VA, and when alcoholic fermentation was finished, the must was inoculated with 0 . oeni 217 . The fermentations were carried out in 1.8-L vessels with $1.5 \mathrm{~L}$ of must and $50 \mathrm{~mL}$ of a single yeast suspension grown in Yeast Extract, Peptone, Dextrose (YEPD) liquid medium. To reach a sufficient and equal yeast population, the Sc. pombe suspensions were cultivated at $24^{\circ} \mathrm{C}$ for $72 \mathrm{~h}$ and the $S$. cerevisiae suspensions were cultivated at $24{ }^{\circ} \mathrm{C}$ for $48 \mathrm{~h}$. The fermentation vessel was sealed with a Müller valve (Alamo, Madrid, Spain) filled with $\mathrm{H}_{2} \mathrm{SO}_{4}$ (Panreac, Barcelona, Spain), which allowed the release of $\mathrm{CO}_{2}$ while avoiding microbial contamination (Martini and Vaughan-Martini, 1998). The initial yeast population was calculated as approximately $10^{6} \mathrm{CFU} / \mathrm{mL}$ (Fig. 1). Fermentation was accomplished at a stabilized room temperature of $25{ }^{\circ} \mathrm{C}$. Samples of approximately $1.5 \mathrm{~mL}$ were taken every few days to monitor the fermentation and other compounds as explained later. At the end of the fermentation, the wine was transferred into $750-\mathrm{mL}$ clear glass bottles, sealed with a natural cork and placed in a cold room at $4{ }^{\circ} \mathrm{C}$ to settle until the sensory analysis session (2 months).

\subsection{Microvinification growth kinetics}

During fermentation, aliquots were taken periodically under aseptic conditions and further serial ten-fold dilutions were made. Every time a sample was taken, the vessel was stirred manually to obtain a representative sample. Growth kinetics were monitored by plating $20 \mu \mathrm{L}$ of the appropriate dilution on Petri dishes containing Yeast Extract Peptone Dextrose agar medium. Colonies were counted after incubation at $30{ }^{\circ} \mathrm{C}$ for $48-72$ h. Sc. pombe colonies were differentiated from S. cerevisiae colonies by diameter, size and microscopic observation.

\subsection{Analytical determinations of non-volatile compounds}

Glucose and fructose, malic, lactic, acetic, pyruvic and citric acids, glycerol, and acetaldehyde were determined with a Y15 enzymatic autoanalyzer (Biosystems S.A., Barcelona, Spain). These analyses were performed using the appropriate kits from Biosystems (http://www. biosystems.es). The Y15 equipment was calibrated with the external standards that are provided in every kit by Biosystems. The alcohol content was determined following the International Methods of Analysis of Wines and Musts (OIV, 2015).

\subsection{Analytical determination of anthocyanins}

The following anthocyanins and pyronoanthocyanins, all of which influence wine quality, were determined at the end of the alcoholic and malolactic fermentations: delphinidin-3-0-glucoside (D3G). cyanidin-3-O-glucoside (C3G), petunidin-3-O-glucoside (Pt3G), peonidin-3-O-glucoside (Pn3G), malvidin-3-O-glucoside (M3G), Vitisine B (Vit B), Vitisine A (VitA), delphinidin-3-O-(6"acetylglucoside) (D3G Ac), cyanidin-3-O-(6"-acetylglucoside) (C3G Ac), petunidin-3-O-(6"-acetylglucoside) (Pt3G Ac), peonidin-3-O-(6"acetylglucoside) (Pn3G Ac), malvidin-3-O-(6"-acetylglucoside) (M3G Ac), cyanidin-3-0-(6"-p-coumaroylglucoside) (C3G Cm), petunidin-3-0-(6"-p-coumaroylglucoside) (Pt3G Cm), malvidin-3-O(6"-p-coumaroylglucoside) (M3G Cm), malvidin-3-O-glucoside-4vinylphenol (M3G Vph), Vinifera anthocyanin (Vinf), malvidin-3-Oglucoside-4-vinylguaiacol (M3G GVG), and malvidin-3-0-(6"-pcoumaroylglucoside)-vinylphenol (M3Gcm Vph). All substances were monitored by high-performance liquid chromatography using an Agilent Technologies series 1200 infinity series with a diode array detector (Hewlett-Packard, Palo Alto, CA, USA). Gradients of solvent C (water/formic acid, 95:5, v/v) and D (methanol/formic acid, 95:5, v/v) were used in a reverse-phase Poroshell 120 (Hewlett-Packard, Palo Alto, CA, USA) ( $5 \mathrm{~cm}$; particle size $2.7 \mu \mathrm{m}$ ) as follows: a linear gradient of $85 \% \mathrm{C}$ and $15 \% \mathrm{D}(1 \mathrm{~mL} / \mathrm{min})$ from 0 to $2 \mathrm{~min}$, a linear gradient of $85-50 \% \mathrm{C}$ and $15-20 \% \mathrm{D}(1 \mathrm{~mL} / \mathrm{min})$ from 2 to $10 \mathrm{~min}$, a linear gradient of $50 \% \mathrm{C}$ and $50 \% \mathrm{D}(1 \mathrm{~mL} / \mathrm{min})$ from $10-12 \mathrm{~min}$ and re-equilibration of the column from 12 to 13 min to $15 \mathrm{~min}$. Detection was performed by scanning in the 250-600 $\mathrm{nm}$ range. Calibration was performed using malvidin-3-O-glucoside (Extrasynthese, Geney, France) as an external standard. The R2 value obtained was greater than 0.999 . The sensitivity was higher than $0.1 \mathrm{mg} / \mathrm{L}$. Malvidin-3-O-glucoside controls were used to verify the calibration in each sequence. Wine samples $(20 \mu \mathrm{L})$ of previously filtered $(0.45-\mu \mathrm{m}$ membrane filters made of cellulose methylic esters (Teckorama, Barcelona, Spain)) were injected into the HPLC apparatus. The different anthocyanins were identified by their retention times with respect to the majority anthocyanin malvidin-3-O-glucoside and by comparing the UV-visible spectra with literature data (Heier et al., 2002; Morata et al., 2007).

\subsection{Analytical determinations of volatile compounds}

The concentrations of 18 volatile compounds (methanol, npropanol, diacetyl, ethyl acetate, iso-butanol, n-butanol, 2-butanol, amylic alcohol, isoamylic alcohol, isobutyl acetate, ethyl butyrate, ethyl lactate, n-hexanol, isoamyl acetate, 2-phenylethyl alcohol, 2phe-nylethyl acetate and 2,3-butanediol), all of which influence wine quality, were measured at the end of the alcoholic and malolactic fermentations by gas chromatography using an Agilent Technologies 
Sc. pombe 2139

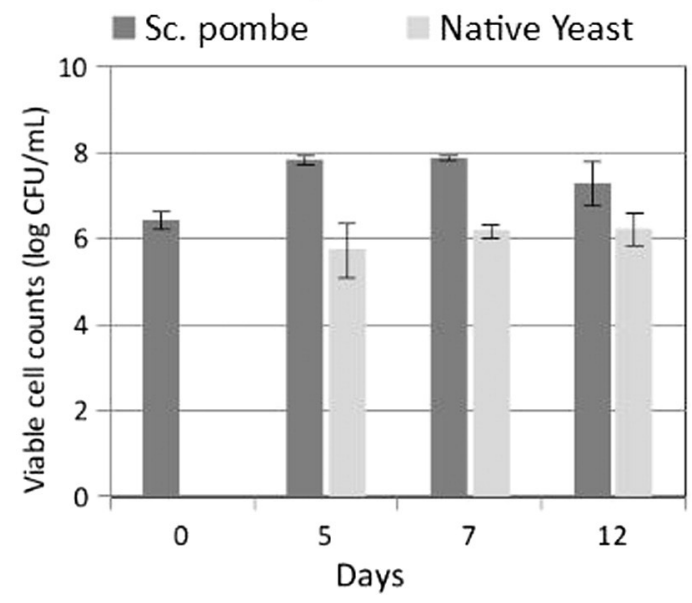

Sc. pombe V1

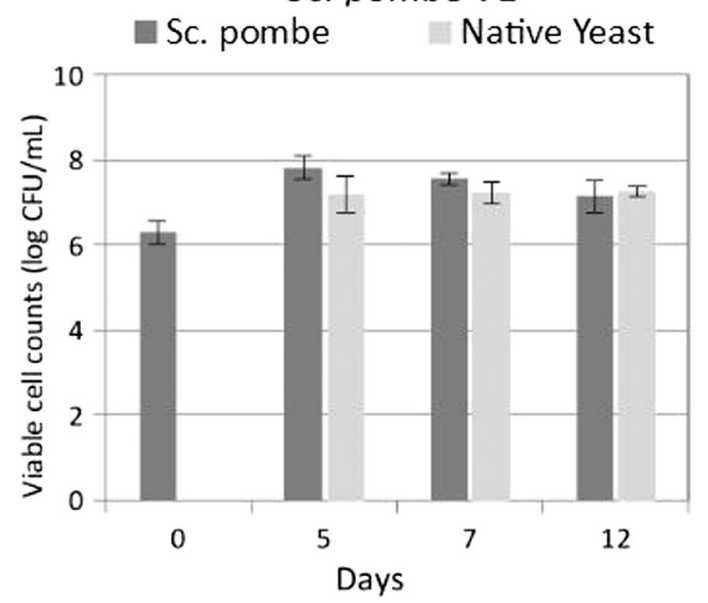

Sc. pombe 938

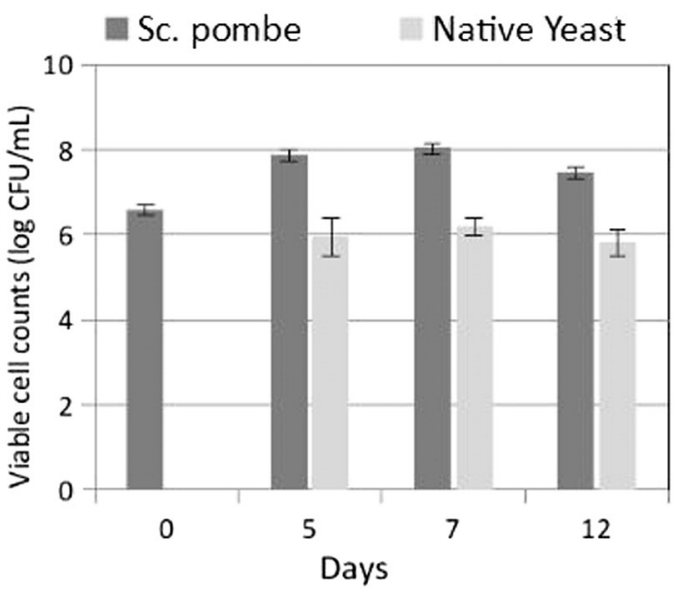

Sc.pombe 4.2

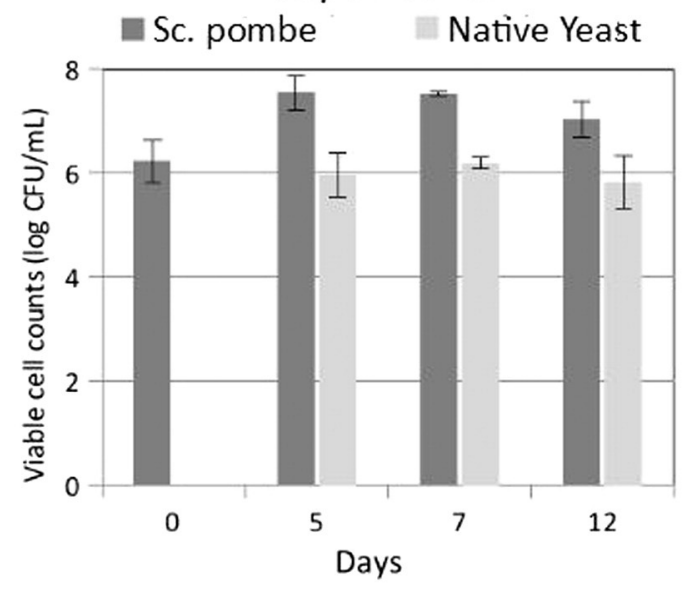

\section{S.cerevisiae 7VA}

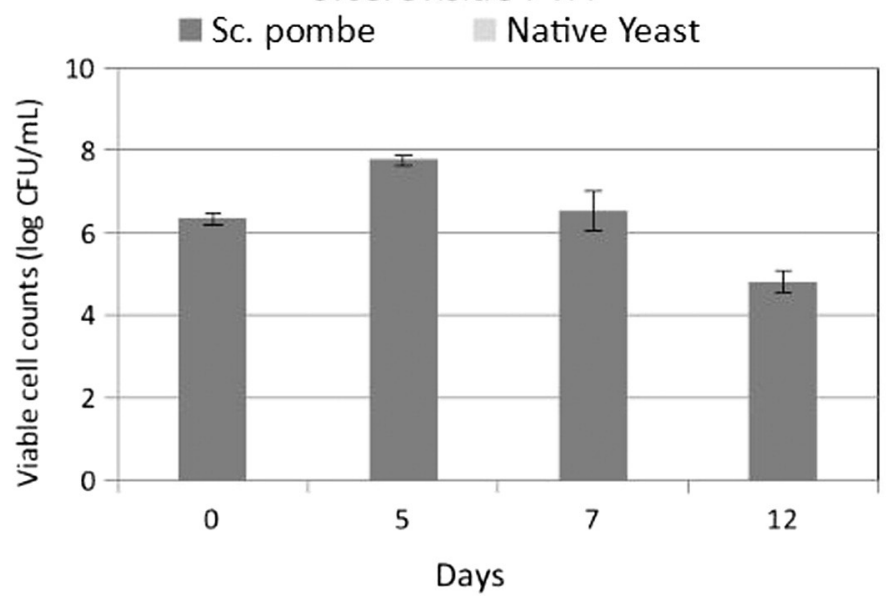

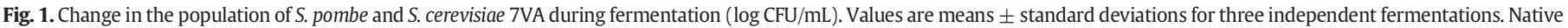
yeast were counted in all fermentations.

6850 gas chromatograph with a flame ionization detector (HewlettPackard, Palo Alto, CA, USA). The apparatus was calibrated with a 4meth-yl-2-pentanol internal standard at $50 \mathrm{mg} / \mathrm{L}$. Gas chromatography quality reagents (Fluka, Sigma-Aldrich Corp., Buchs SG, Switzerland) were used as standards. Higher alcohols were separated as described in the International Methods of the Analysis of Musts and Wines (OIV,
2015). An individual calibration for each volatile compound was accomplished using an external standard at six concentrations ranging from 1 to $500 \mathrm{mg} / \mathrm{L}$, except for 2,3-butanediol, which ranged from 100 to $1000 \mathrm{mg} / \mathrm{L}$ in accordance with its mean concentration in wine. The R2 values were greater than 0.999 for all compounds tested. The detection limit of the method was $0.1 \mathrm{mg} / \mathrm{L}$. 


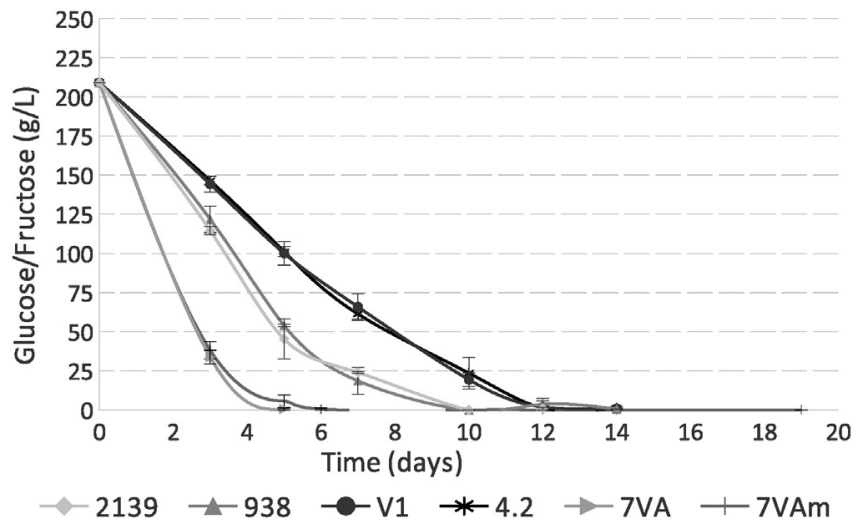

Fig. 2. Change in the glucose/fructose content of Tempranillo must during fermentation. The following nomenclature is used: Assays fermented with wild Sc. pombe strains 2139 and 938, selected Sc. pombe strains V1 and 4.2, S. cerevisiae 7VA, and the letter $\mathrm{m}$ indicates assays in which malolactic fermentation with Oenococcus oeoni 217 occurred.

\subsection{Analytical determination of biogenic amines}

Biogenic amines were determined using a Jasco (Tokyo, Japan) UHPLC chromatograph series X-LCTM, equipped with a 3120-FP fluorescence detector. Gradients of solvent A (methanol/acetonitrile, 50:50, v/v) and B (sodium acetate /tetrahydrofuran, 99:1, v/v) were used in a C18 (HALO, USA) column $(100 \mathrm{~mm} \times 2.1 \mathrm{~mm}$; particle size $2.7 \mu \mathrm{m})$ as follows: $60 \% \mathrm{~B}(0.25 \mathrm{~mL} / \mathrm{min})$ from 0 to $5 \mathrm{~min}$, a linear gradient of $60-50 \%$ B $(0.25 \mathrm{~mL} / \mathrm{min})$ from 5 to $8 \mathrm{~min}, 50 \%$ B from 8 to $9 \mathrm{~min}$, a linear gradient of $50-20 \% \mathrm{~B}(0.2 \mathrm{~mL} / \mathrm{min})$ from 9 to $12 \mathrm{~min}, 20 \% \mathrm{~B}$ $(0.2 \mathrm{~mL} / \mathrm{min})$ from 12 to $13 \mathrm{~min}$, a linear gradient of $20-60 \% \mathrm{~B}$ ( $0.2 \mathrm{~mL} / \mathrm{min}$ ) from 13 to $14.5 \mathrm{~min}$, and re-equilibration of the column from 14.5 to $17 \mathrm{~min}$. Detection was performed by scanning in the $340-420 \mathrm{~nm}$ range. Quantification was performed by comparison against external standards. Different biogenic amines were identified by their retention times.

\subsection{Color measurements}

An Agilent 8453 UV-Visible ChemStation diode array spectrophotometer (Santa Clara, USA) was used for the analysis. Samples were analyzed in a quartz cuvette with a 1-mm path length and a range of 200 to $1100 \mathrm{~nm}$, following the procedure of Glories (Glories, 1984a, 1984b). Absorbance at $420 \mathrm{~nm}, 520 \mathrm{~nm}$, and $620 \mathrm{~nm}$ was measured. Color intensity was calculated as the sum of absorbance at the three wavelengths, while the tonality (hue) was calculated as the ratio between the absorbance at $420 \mathrm{~nm}$ and $520 \mathrm{~nm}$.

\subsection{Sensory analysis}

The experimental wines were evaluated by a team of (12) experienced wine tasters ( 7 females and 5 males), 6 employees of the
Chemistry and Food Technology Department (Madrid, Spain) and 6 students. Five visual descriptors, eight taste parameters and 10 aromas were used to evaluate the final fermentations. No specific training was carried out prior to the tasting session. Six wines were evaluated in a randomized order. The wines were presented in clear tasting glasses identified with numbers from one to six in an air-conditioned $\left(20^{\circ} \mathrm{C}\right)$ tasting room. Twenty five milliliters of each wine was served at $14{ }^{\circ} \mathrm{C}$. The panelists were asked to rate the wines for 23 attributes after tasting on an unstructured scale of 0 to 5 , with 0 (absent) to 5 (very intense). Additionally, the panelists were asked to name descriptors as free comments for each wine.

\subsection{Statistical analysis}

All statistical analyses were performed using the Rstudio program software (Version 0.98.501-@ ( 2009-2013 Rstudio, Inc.). The significance was set to $\mathrm{p}<0.05$ for the ANOVA matrix F value. Tukey's Studentized Range (HSD) test was used to compare the means.

\section{Results and discussion}

\subsection{Fermentation microbiology}

The results of the yeast count of the Tempranillo must prior to inoculation were $10^{5} \mathrm{CFU} / \mathrm{mL}$ for the refrigerated must and $1.6 \cdot 10^{2} \mathrm{CFU} / \mathrm{mL}$ for the pasteurized must. The results of the yeast counts during fermentation are shown in Fig. 1. The Sc. pombe cell population varied from $10^{6}$ to $10^{8}$ during fermentation, while the native yeast remained 2 log scale units below the inoculated population (Fig. 1), which was directly related to the malic acid degradation by Sc. Pombe, as explained below.

\subsection{Fermentation kinetics}

\subsubsection{Sugars and malic acid}

Fig. 2 shows the change in the glucose/fructose concentration over the fermentation period. The fermentation kinetics was acceptable for every fermentation; fermentations were concluded at approximately the 6 th day in the $S$. cerevisiae assays and at approximately the 14th day for Sc. pombe 2139, 938, V1 and 4.2. Previous studies have also reported slower fermentation by Schizosaccharomyces (Benito et al., 2012, 2013). In those cases, the fermentation times for Sc. pombe varied from 10 to 19 days, while the Saccharomyces controls varied from 6 to 10 days. The difference between Sc. pombe V1 and 4.2 and the wild Sc. pombe 2139 and 938 was evident because strains V1 and 4.2 consumed the sugar in the must more slowly than the wild strains. Even the sugar consumption kinetics are slower for S. pombe; the wines do not need to perform the malolactic fermentation, which usually takes longer than the alcoholic one. The data showed that the fermentation kinetics of the selected Sc. pombe strains was more nearly linear than those of the wild strains and that the wild strains had more similar fermentation kinetics to S. cerevisiae even though they were slightly slower. In each

Table 1

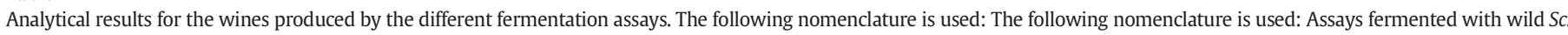

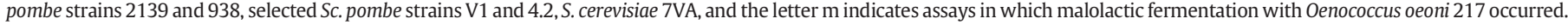

\begin{tabular}{|c|c|c|c|c|c|c|}
\hline Compounds & 2139 & 938 & V1 & 4.2 & 7VA & 7VAm \\
\hline Pyruvic Acid (mg/L) & $352.33 \pm 6.66^{\mathrm{a}}$ & $330.67 \pm 8.50^{\mathrm{a}}$ & $191.00 \pm 5.00^{\mathrm{b}}$ & $193.00 \pm 2.65^{\mathrm{b}}$ & $219.67 \pm 57.20^{\mathrm{b}}$ & $36.33 \pm 5.51^{c}$ \\
\hline L-Lactic Acid (g/L) & $0.16 \pm 0.06^{\mathrm{a}}$ & $0.14 \pm 0.14^{\mathrm{a}}$ & $0.00 \pm 0.00^{\mathrm{a}}$ & $0.14 \pm 0.14^{\mathrm{a}}$ & $0.10 \pm 0.09^{\mathrm{a}}$ & $1.79 \pm 0.26^{\mathrm{b}}$ \\
\hline Glucose/Fructose (g/L) & $0.88 \pm 0.84^{\mathrm{a}}$ & $0.54 \pm 0.23^{\mathrm{a}}$ & $0.86 \pm 0.45^{\mathrm{a}}$ & $1.22 \pm 1.18^{\mathrm{a}}$ & $0.89 \pm 0.18^{\mathrm{a}}$ & $0.05 \pm 0.09^{\mathrm{a}}$ \\
\hline Glycerol (g/L) & $6.18 \pm 0.38^{\mathrm{bc}}$ & $5.99 \pm 0.58^{\mathrm{bc}}$ & $6.52 \pm 0,62^{\mathrm{ab}}$ & $7.55 \pm 0.43^{\mathrm{a}}$ & $5.30 \pm 0.17^{c}$ & $5.35 \pm 0.25^{\mathrm{bc}}$ \\
\hline Citric Acid (mg/L) & $401.67 \pm 7.02^{c}$ & $465.00 \pm 5.57^{\mathrm{abc}}$ & $500.67 \pm 25.15^{\mathrm{ab}}$ & $508.00 \pm 45.51^{\mathrm{a}}$ & $513.00 \pm 47.00^{\mathrm{a}}$ & $423.00 \pm 6.08^{\mathrm{bc}}$ \\
\hline L-Malic Acid (g/L) & $0.04 \pm 0.07^{\mathrm{a}}$ & $0.00 \pm 0.00^{\mathrm{a}}$ & $0.00 \pm 0.00^{\mathrm{a}}$ & $0.08 \pm 0.14^{\mathrm{a}}$ & $3.76 \pm 0.50^{\mathrm{b}}$ & $0.17 \pm 0.06^{\mathrm{a}}$ \\
\hline Acetic Acid (g/L) & $1.01 \pm 0.24^{\mathrm{a}}$ & $1.12 \pm 0.11^{\mathrm{a}}$ & $0.35 \pm 0.02^{\mathrm{c}}$ & $0.31 \pm 0.08^{c}$ & $0.51 \pm 0.06^{\mathrm{b}}$ & $0.59 \pm 0.10^{\mathrm{b}}$ \\
\hline Acetaldehyde (mg/L) & $29.33 \pm 1.53^{b}$ & $27.00 \pm 3.00^{\mathrm{b}}$ & $76.00 \pm 1.00^{\mathrm{a}}$ & $69.67 \pm 7.64^{\mathrm{a}}$ & $85.00 \pm 16.00^{\mathrm{a}}$ & $3.33 \pm 0.58^{c}$ \\
\hline $\mathrm{pH}$ & $3.49 \pm 0.03^{c}$ & $3.50 \pm 0.02^{\mathrm{c}}$ & $3.47 \pm 0.03^{c}$ & $3.49 \pm 0.02^{\mathrm{c}}$ & $3.14 \pm 0.02^{\mathrm{a}}$ & $3.29 \pm 0.03^{b}$ \\
\hline
\end{tabular}

Results represent the mean \pm SD for three replicates. Means in the same row with the same letter are not significantly different $(\mathrm{p}<0.05)$. 


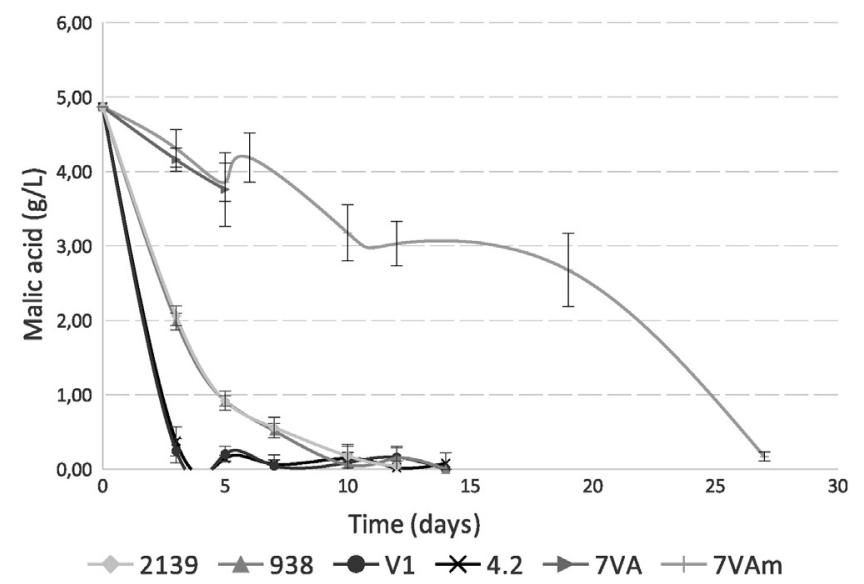

Fig. 3. Change in the malic acid content of Tempranillo must during fermentation. The following nomenclature is used: Assays fermented with wild Sc. pombe strains 2139 and 938, selected Sc. pombe strains V1 and 4.2, S. cerevisiae 7VA, and the letter $\mathrm{m}$ indicates assays in which malolactic fermentation with Oenococcus oeoni 217 occurred.

fermentation, all of the wine produced had a residual sugar content of less than $2 \mathrm{~g} / \mathrm{L}$ (Table 1 ) and an alcohol content of approximately $12 \%$ by volume. In contrast, other authors have shown that some non-Saccharomyces yeast produced a lower yield of ethanol than Saccharomyces (Kutyna et al., 2010; Gobbi et al., 2014; Contreras et al., 2014). Previous studies with S. pombe have showed slight reductions up to $0.5 \mathrm{~g} / \mathrm{L}$ when compared to the Saccharomyces control (Benito et al., 2013) in some instances. Other authors observed a higher final ethanol reduction over $1 \%$ by volume using other non-Saccharomyces species under specific conditions of high aeration (Contreras et al., 2015; Morales et al., 2015).

Malic acid has a "harsh" mouthfeel and can reduce wine quality in high concentrations. Fig. 3 shows the potential of Sc. pombe as a biological deacidifier, which can be easily seen by the changes in the malic acid content in the under fermentation must. It is evident that the assays with Sc. pombe strains V1 and 4.2 have faster and different kinetics than those of Sc. pombe 2139 and 938. For the selected Sc. pombe, the malic acid was totally consumed by day 7 , but in the case of the wild ones, it was day 10 , indicating that the selected Sc. pombe preferentially consumed malic acid. This is also in agreement with previous studies in which $75-100 \%$ reductions in the malic acid content were noted depending on the Schizosaccharomyces strain used (Benito et al., 2014c; De Fatima et al., 2007; Gao and Fleet, 1995; Magyar and Panyik, 1989; Silva et al., 2003; Snow and Gallander, 1979; Taillandier et al., 1995; Thornton and Rodriguez, 1996). In those studies, malic acid degradation varied from 5 to 10 days depending on the strain. After allowing malolactic fermentation to proceed in the assay fermented with $S$. cerevisiae 7VA, the final lactic acid concentration recorded was $1.79 \mathrm{~g} / \mathrm{L}$ (Table 1). The level of citric acid diminished by approximately $0.1 \mathrm{~g} / \mathrm{L}$ after the malolactic fermentation. Other authors have reported reductions up to $0.3 \mathrm{~g} / \mathrm{L}$ of citric acid by lactic acid bacteria during a malolactic fermentation; in such cases, the citric acid metabolism was accompanied by increases in the acetic acid, acetoin and diacetyl concentrations that decreased the wine quality (Shimazu et al., 1985). No significant differences were seen in the malic acid content at the end of the maloalcoholic and malolactic fermentations in any of the experiments (Table 1). The final $\mathrm{pH}$ was higher for the Sc. pombe fermentations due to the consumption of malic acid without the production of lactic acid (Table 1). However, the pH remained lower in both of the S. cerevisiae fermentations. In one experiment, a malolactic fermentation did not occur as evidenced by a final malic acid concentration of $3.76 \mathrm{~g} / \mathrm{L}$, and in another experiment, a malolactic fermentation did occur, as evidenced by the conversion of malic acid into $1.79 \mathrm{~g} / \mathrm{L}$ (Table 1 ) of lactic acid by the lactic acid bacteria.

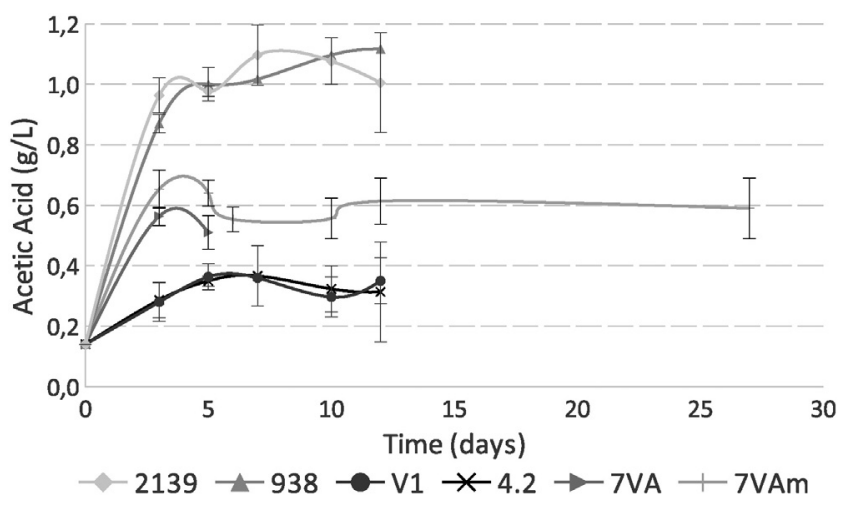

Fig. 4. Change in the acetic acid content of Tempranillo must during fermentation. The following nomenclature is used: Assays fermented with wild Sc. pombe strains 2139 and 938, selected Sc. pombe strains V1 and 4.2, S. cerevisiae 7VA, and the letter m indicates assays in which malolactic fermentation with Oenococcus oeoni 217 occurred. a. Acetic acid concentrations in the final Tempranillo wines. The following nomenclature is used: Assays fermented with wild Sc. Pombe strains 2139 and 938, selected Sc. Pombe strains $\mathrm{V} 1$ and 4.2 , S. cerevisiae 7VA, and the letter $\mathrm{m}$ indicates assays in which malolactic fermentation with Oenococcus oeoni 217 occurred.

\subsubsection{Acetic acid}

As previously mentioned, a primary enological concern associated with Schizosaccharomyces spp. is its significant production of greater than $1 \mathrm{~g} / \mathrm{L}$ of acetic acid in a laboratory-scale fermentation (Benito et al., 2012, 2014b). Acetic acid has a negative impact on wine flavor, and low levels usually produce better sensory profiles. Levels over $0.8 \mathrm{~g} / \mathrm{L}$ can generate wine quality problems. In the present study, the acetic acid content became relatively stable on approximately day 8 of the fermentation (Fig. 4). Fig. 4a shows the final acetic acid concentration. In the fermentations involving Sc. pombe V1 and 4.2, the concentration of acetic acid remained at approximately $0.30 \mathrm{~g} / \mathrm{L}$ from day 5 until the end of fermentation and remained approximately at $1 \mathrm{~g} / \mathrm{L}$ for Sc. pombe 2139 and 938 (Fig. 4). Other authors have reported a final acetic acid value of approximately $0.4 \mathrm{~g} / \mathrm{L}$ for a few selected Schizosaccharomyces strains in small-scale trials (Benito et al., 2014b). Acetic acid production is a strain-dependent characteristic of Schizosaccharomyces species that varied from 0.4 to $1.3 \mathrm{~g} / \mathrm{L}$ in previous studies, commonly averaging between 0.6 and $0.9 \mathrm{~g} / \mathrm{L}$ (Benito et al., 2014b). However, S. cerevisiae alone increased the acetic acid concentration (Fig. 4a) greater than strains V1 and 4.2, and it was even higher following the malolactic fermentation step, reaching a value of $0.59 \mathrm{~g} / \mathrm{L}$ of acetic acid. That finding confirms that a well-chosen Sc. pombe strain can have results as good as S. cerevisiae for low acetic acid production.

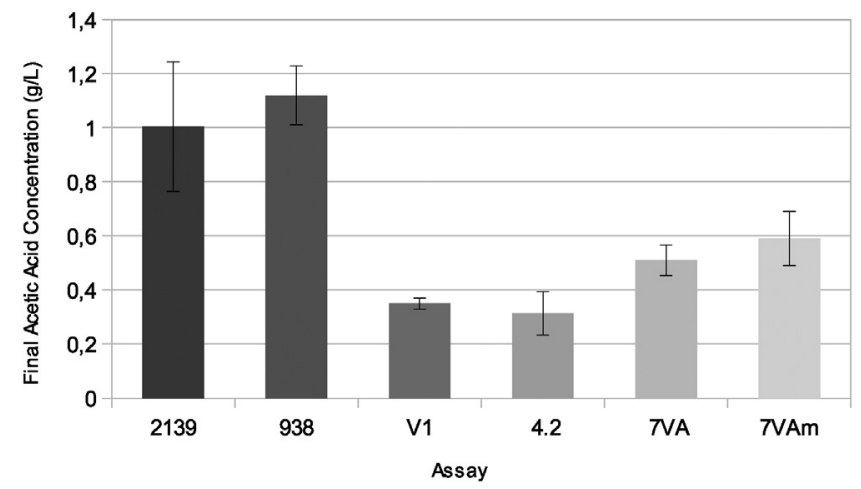

Fig. 5. Change in the pyruvic acid content of Tempranillo must during fermentation. The following nomenclature is used: Assays fermented with wild Sc. Pombe strains 2139 and 938, selected Sc. Pombe strains V1 and 4.2, S. cerevisiae 7VA, and the letter m indicates assays in which malolactic fermentation with Oenococcus oeoni 217 occurred. 
Table 2

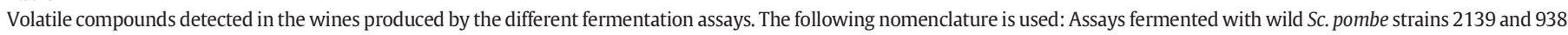
selected Sc. pombe strains V1 and 4.2, S. cerevisiae 7VA, and the letter m indicates assays in which malolactic fermentation with Oenococcus oeoni 217 occurred.

\begin{tabular}{|c|c|c|c|c|c|c|}
\hline $\begin{array}{l}\text { Compounds } \\
(\mathrm{mg} / \mathrm{L})\end{array}$ & 2139 & 938 & V1 & 4.2 & $7 \mathrm{VA}$ & 7VAm \\
\hline Methanol & $38.82 \pm 1.30^{\mathrm{a}}$ & $40.92 \pm 0.50^{\mathrm{a}}$ & $41.64 \pm 1.09^{a}$ & $41.62 \pm 1.74^{\mathrm{a}}$ & $40.78 \pm 1.66^{\mathrm{a}}$ & $41.57 \pm 2.48^{\mathrm{a}}$ \\
\hline 1-propanol & $28.48 \pm 2.82^{\mathrm{ab}}$ & $29.41 \pm 1.21^{\mathrm{a}}$ & $23.72 \pm 0.72^{\mathrm{c}}$ & $24.85 \pm 0.02^{\mathrm{bc}}$ & $28.21 \pm 0.91^{\mathrm{ab}}$ & $28.86 \pm 1.44^{\mathrm{ab}}$ \\
\hline Diacetyl & $3.98 \pm 0.23^{\mathrm{d}}$ & $4.00 \pm 0.31^{\mathrm{d}}$ & $5.26 \pm 0.01^{c}$ & $5.50 \pm 0.33^{c}$ & $3.72 \pm 0.28^{\mathrm{d}}$ & $14.89 \pm 3.19^{b}$ \\
\hline Ethyl acetate & $76.87 \pm 9.49^{a}$ & $74.36 \pm 7.02^{\mathrm{a}}$ & $43.19 \pm 2.35^{\mathrm{b}}$ & $44.17 \pm 5.61^{b}$ & $63.26 \pm 2.76^{\mathrm{a}}$ & $77.23 \pm 3.19^{a}$ \\
\hline 2-butanol & $2.77 \pm 0.88$ & - & - & - & - & - \\
\hline Isobutanol & $8.02 \pm 1.53^{c}$ & $8.51 \pm 0.88^{c}$ & $31.47 \pm 0.91^{\mathrm{b}}$ & $30.43 \pm 0.12^{b}$ & $120.60 \pm 11.27^{\mathrm{a}}$ & $115.25 \pm 12.78^{a}$ \\
\hline 1-butanol & $22.16 \pm 6.44^{\mathrm{a}}$ & $15.49 \pm 4.92^{\mathrm{ab}}$ & $13.51 \pm 7.55^{\mathrm{abc}}$ & $8.09 \pm 0.69^{b c}$ & $18.09 \pm 2.30^{\mathrm{ab}}$ & $5.20 \pm 1.41^{\mathrm{bc}}$ \\
\hline Acetoin & $103.34 \pm 9.33^{a}$ & $93.26 \pm 6.69^{a}$ & $51.41 \pm 0.45^{\mathrm{b}}$ & $42.93 \pm 5.84^{b}$ & $11.60 \pm 0.25^{c}$ & $23.50 \pm 1.31^{\mathrm{c}}$ \\
\hline 2-methyl-1-butanol & $25.84 \pm 3.77 c$ & $28.02 \pm 1.67^{c}$ & $111.48 \pm 0.74^{\mathrm{b}}$ & $111.62 \pm 1.78^{\mathrm{b}}$ & $257.40 \pm 25.64^{a}$ & $277.30 \pm 17.08^{a}$ \\
\hline 3-methyl-1-butanol & $14.47 \pm 3.47^{c}$ & $13.63 \pm 0.36^{\mathrm{c}}$ & $28.13 \pm 2.89^{b}$ & $27.92 \pm 1.49^{\mathrm{b}}$ & $59.20 \pm 5.15^{\mathrm{a}}$ & $65.08 \pm 0.87^{\mathrm{a}}$ \\
\hline Isobutyl acetate & - & - & - & - & - & - \\
\hline Ethyl butyrate & - & - & - & - & $2.22 \pm 0.12$ & - \\
\hline Ethyl lactate & $9.78 \pm 0.20^{\mathrm{c}}$ & $11.37 \pm 3.32^{c}$ & $9.80 \pm 0.69^{c}$ & $8.83 \pm 1.03^{c}$ & $18.43 \pm 0.75^{\mathrm{b}}$ & $76.50 \pm 2.61^{\mathrm{a}}$ \\
\hline $2-3$ butanodiol & $216.20 \pm 0.45^{c}$ & $237.56 \pm 19.08^{c}$ & $305.25 \pm 9.32^{\mathrm{b}}$ & $322.43 \pm 25.76^{\mathrm{b}}$ & $451.01 \pm 18.21^{\mathrm{a}}$ & $476.64 \pm 42.74^{\mathrm{a}}$ \\
\hline Isoamyl acetate & $3.72 \pm 0.13^{\mathrm{e}}$ & $13.63 \pm 0.36^{\mathrm{b}}$ & $7.66 \pm 0.77^{\mathrm{d}}$ & $7.42 \pm 0.03^{\mathrm{d}}$ & $10.81 \pm 0.75^{c}$ & $9.40 \pm 1.49^{c d}$ \\
\hline Hexanol & $4.22 \pm 0.13^{\mathrm{a}}$ & $3.79 \pm 0.01^{\mathrm{a}}$ & - & $3.98 \pm 0.28^{\mathrm{a}}$ & $4.10 \pm 0.31^{\mathrm{a}}$ & - \\
\hline 2-phenylethanol & $34.81 \pm 2.29^{b}$ & $37.34 \pm 2.57^{b}$ & $39.00 \pm 0.43^{\mathrm{b}}$ & $40.26 \pm 0.49^{b}$ & $78.46 \pm 0.18^{a}$ & $86.26 \pm 7.60^{\mathrm{a}}$ \\
\hline Phenylethyl acetate & $8.50 \pm 0.14^{\mathrm{a}}$ & $8.02 \pm 0.19^{\mathrm{ab}}$ & $7.11 \pm 0.17^{\mathrm{b}}$ & $6.98 \pm 0.18^{\mathrm{b}}$ & $7.80 \pm 0.08^{\mathrm{ab}}$ & $9.03 \pm 0.33^{\mathrm{a}}$ \\
\hline
\end{tabular}

Results represent the mean \pm SD for three replicates. Means in the same row with the same letter are not significantly different $(\mathrm{p}<0.05$ ).

\subsubsection{Pyruvic acid}

Fig. 5 shows the change in the pyruvic acid concentration during fermentation. High levels of pyruvic acid are related to the formation of highly stable pigments such as vitisin A, which improves the chromatic characteristics of wines, especially during a long aging processes (Morata et al., 2003) when stable pigment forms become more important than unstable forms. The maximum concentration was reached on day 3 for S. cerevisiae and on day 5 for the Sc. pombe strains, followed by its reduction. The maximum concentration was achieved with the wild Sc. pombe. S. cerevisiae fermentation without a malolactic fermentation (MLF), which showed a higher than usual concentration of pyruvic acid that could be explained by the higher than usual speed of the fermentation process. S. cerevisiae showed much lower values when an MLF was subsequently performed. In other studies involving fermentations with other Schizosaccharomyces strains, values up to $0.39 \mathrm{~g} / \mathrm{L}$ have been recorded (Benito et al., 2012). The pyruvic acid concentrations reached in fermentations with wild Sc. pombe were almost double that with the selected Sc. pombe but were also higher than that with S. cerevisiae 7VA, which was chosen for its ability to produce a high amount of pyruvic acid. The formation of highly stable pigments such as vitisin A in fermentations with wild Sc. pombe strains should probably be higher than the rest.

\subsubsection{Glycerol}

The final glycerol content of wine produced by different yeast was higher in the Sc. pombe fermentations. The highest value detected was $7.55 \mathrm{~g} / \mathrm{L}$ for Sc. pombe 4.2, while the lowest was $5.30 \mathrm{~g} / \mathrm{L}$ for S. cerevisiae 7VA (Table 1). Schizosaccharomyces species have previously been reported to produce more glycerol than Saccharomyces species, reaching values up to $10 \mathrm{~g} / \mathrm{L}$ and approximately $1 \mathrm{~g} / \mathrm{L}$ higher than the Saccharomyces control (Benito et al., 2014b). Some authors have reported that some Sc. pombe strains have a well-developed glyceropyruvic pathway, which might explain the slightly higher pyruvic acid and glycerol production compared to other yeast (Suárez-Lepe and Leal, 2004). An increased glycerol content has been described as one of the primary contributions of non-Saccharomyces strains to wine quality (Jolly et al., 2006) because it enriches the mouth-feel. Other authors have reported higher glycerol production for other non-Saccharomyces species (Comitini et al., 2011; Gobbi et al., 2013). Although other yeast species such as Candida stellata have been described as higher producers of glycerol up to
$14 \mathrm{~g} / \mathrm{L}$ (Jolly et al., 2014), the use of Schizosaccharomyces to improve this quality parameter could be interesting.

\subsubsection{Acetaldehyde}

The experiments with the selected Sc. pombe V1 and 4.2 strains and S. cerevisiae without malolactic fermentation had the highest final acetaldehyde content, while the experiment with the S. cerevisiae with MLF had the lowest (Table 1 ). High acetaldehyde values could be beneficial for red wine because, along with malvidin-3-glucoside, it acts as a precursor of vitisin B, which helps stabilize wine color (Benito et al., 2011).

\subsection{Volatile aromas}

Table 2 shows the production of volatile compounds in the different fermentations. Methanol production (approximately $40 \mathrm{mg} / \mathrm{L}$ ) never exceeded the legal limit of $120 \mathrm{mg} / \mathrm{L}$ for red wine. At the end of all fermentations, the ethyl acetate that was produced was approximately $77 \mathrm{mg} / \mathrm{L}$, which is considered acceptable because it is below the threshold of $150 \mathrm{mg} / \mathrm{L}$ considered to be undesirable (Rapp et al., 1992; Lambrechts and Pretorius, 2000); higher levels could be responsible for an undesirable glue odor. The highest values were achieved with the wild Sc. pombe strains but also with the S. cerevisiae with or without subsequent MLF. The lowest values were achieved for the selected V1 and 4.2 Sc. Pombe that produced concentrations $20 \mathrm{mg} / \mathrm{L}$ lower than the others, which could influence the wine quality in a positive way. MLF did not seem to have an effect on ethyl acetate production, but it was highly strain-dependent in Sc. Pombe fermentations.

Higher alcohols (isobutanol, 2-methyl-1-butanol and 3-methyl-1butanol) were produced in the highest quantities in the S. cerevisiae fermentations, both before and after the malolactic fermentation step. The lowest values were produced with the wild Sc. pombe strains 2139 and 938. Other authors have reported that other non-Saccharomyces yeast produced lower amounts of higher alcohols than Saccharomyces cerevisiae (Benito et al., 2015a; Clemente-Jimenez et al., 2004; Gobbi et al., 2013; Parapouli et al., 2010; Romano and Suzzi, 1993; Romano, 2003; Zironi et al., 1993). Sometimes low levels of higher alcohols increased the perception the aroma of varietal grape varieties, which was considered a positive effect (Belda et al., 2015). A total higher alcohol concentration of less than $350 \mathrm{mg} / \mathrm{L}$ is recommended because a higher concentration gives the wine a disagreeable alcoholic flavor. In this study, S. cerevisiae exceeded the recommended value. Nevertheless, 
Table 3

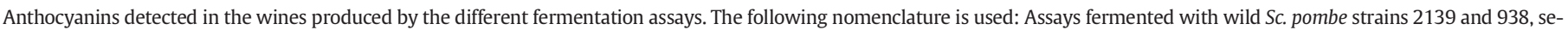
lected Sc. pombe strains V1 and 4.2, S. cerevisiae 7VA, and the letter m indicates assays in which malolactic fermentation with Oenococcus oeoni 217 occurred.

\begin{tabular}{|c|c|c|c|c|c|c|}
\hline $\begin{array}{l}\text { Compounds } \\
(\mathrm{mg} / \mathrm{L})\end{array}$ & 2139 & 938 & V1 & 4.2 & 7VA & 7VAm \\
\hline D3G & $1.30 \pm 0.09^{\mathrm{ab}}$ & $1.13 \pm 0.10^{\mathrm{b}}$ & $0.86 \pm 0.12^{\mathrm{c}}$ & $0.88 \pm 0.05^{c}$ & $1.47 \pm 0.04^{\mathrm{a}}$ & $0.47 \pm 0.04^{\mathrm{d}}$ \\
\hline C3G & $0.62 \pm 0.20^{\mathrm{a}}$ & $0.49 \pm 0.05^{\mathrm{ab}}$ & $0.28 \pm 0.12^{\mathrm{b}}$ & $0.31 \pm 0.08^{\mathrm{b}}$ & $0.34 \pm 0.09^{\mathrm{ab}}$ & - \\
\hline Pt3G & $1.19 \pm 0.04^{b}$ & $1.12 \pm 0.13^{\mathrm{b}}$ & $0.80 \pm 0.10^{c}$ & $0.88 \pm 0.04^{c}$ & $1.6 \pm 0.04^{\mathrm{a}}$ & $0.49 \pm 0.02^{\mathrm{d}}$ \\
\hline Pn3G & $4.42 \pm 0.02^{\mathrm{a}}$ & $4.10 \pm 0.13^{\mathrm{a}}$ & $2.42 \pm 0.39^{\mathrm{b}}$ & $2.62 \pm 0.32^{\mathrm{b}}$ & $4.10 \pm 0.03^{\mathrm{a}}$ & $1.23 \pm 0.14^{\mathrm{c}}$ \\
\hline M3G & $13.23 \pm 0.79^{b}$ & $12.28 \pm 0.09^{\mathrm{a}}$ & $10.45 \pm 0.65^{c}$ & $11.09 \pm 1.23^{\mathrm{c}}$ & $17.47 \pm 0.21^{\mathrm{a}}$ & $5.74 \pm 0.72^{\mathrm{d}}$ \\
\hline VitB & $0.25 \pm 0.00^{\mathrm{a}}$ & $0.23 \pm 0.03^{\mathrm{a}}$ & $0.22 \pm 0.01^{\mathrm{a}}$ & $0.22 \pm 0.03^{\mathrm{a}}$ & $0.15 \pm 0.04^{\mathrm{b}}$ & - \\
\hline VitA & $1.32 \pm 0.01^{\mathrm{a}}$ & $1.28 \pm 0.05^{\mathrm{a}}$ & $1.16 \pm 0.08^{\mathrm{a}}$ & $1.23 \pm 0.10^{\mathrm{a}}$ & $1.25 \pm 0.06^{\mathrm{a}}$ & $0.81 \pm 0.03^{\mathrm{b}}$ \\
\hline D3G Ac & $0.25 \pm 0.02^{\mathrm{a}}$ & $0.22 \pm 0.04^{\mathrm{a}}$ & $0.20 \pm 0.03^{\mathrm{a}}$ & $0.19 \pm 0.05^{\mathrm{a}}$ & $0.30 \pm 0.06^{\mathrm{a}}$ & $0.07 \pm 0.00^{\mathrm{b}}$ \\
\hline $\mathrm{C} 3 \mathrm{G} \mathrm{Ac}$ & $0.49 \pm 0.02^{\mathrm{a}}$ & $0.43 \pm 0.06^{\mathrm{a}}$ & $0.44 \pm 0.03^{a}$ & $0.44 \pm 0.06^{\mathrm{a}}$ & $0.42 \pm 0.05^{\mathrm{a}}$ & $0.32 \pm 0.00^{\mathrm{b}}$ \\
\hline $\mathrm{Pt} 3 \mathrm{G} \mathrm{Ac}$ & $0.47 \pm 0.04^{\mathrm{b}}$ & $0.45 \pm 0.05^{\mathrm{b}}$ & $0.34 \pm 0.05^{\mathrm{bc}}$ & $0.38 \pm 0.01^{c}$ & $0.63 \pm 0.04^{\mathrm{a}}$ & $0.17 \pm 0.01^{\mathrm{d}}$ \\
\hline Pn3G Ac & $0.82 \pm 0.07^{b}$ & $0.81 \pm 0.12^{\mathrm{b}}$ & $0.79 \pm 0.04^{\mathrm{b}}$ & $0.82 \pm 0.07^{\mathrm{b}}$ & $1.21 \pm 0.16^{\mathrm{a}}$ & $0.43 \pm 0.02^{\mathrm{c}}$ \\
\hline M3G Ac & $4.02 \pm 0.20^{\mathrm{b}}$ & $3.74 \pm 0.24^{\mathrm{bc}}$ & $3.18 \pm 0.20^{\mathrm{bc}}$ & $3.41 \pm 0.31^{\mathrm{c}}$ & $4.97 \pm 0.17^{\mathrm{a}}$ & $1.12 \pm 0.17^{\mathrm{d}}$ \\
\hline $\mathrm{C} 3 \mathrm{G} \mathrm{Cm}$ & - & - & - & - & $0.11 \pm 0.01^{\mathrm{a}}$ & - \\
\hline Pt3G Cm & $0.13 \pm 0.05^{\mathrm{a}}$ & $0.14 \pm 0.11^{\mathrm{a}}$ & $0.12 \pm 0.02^{\mathrm{a}}$ & $0.12 \pm 0.01^{\mathrm{a}}$ & $0.14 \pm 0.02^{\mathrm{a}}$ & - \\
\hline M3G Cm & $1.24 \pm 0.11^{\mathrm{ab}}$ & $1.22 \pm 0.11^{\mathrm{ab}}$ & $1.11 \pm 0.10^{\mathrm{a}}$ & $1.22 \pm 0.15^{\mathrm{b}}$ & $1.48 \pm 0.05^{\mathrm{a}}$ & $0.48 \pm 0.04^{\mathrm{c}}$ \\
\hline M3G Vph & - & - & - & - & $0.40 \pm 0.03^{\mathrm{b}}$ & $0.55 \pm 0.01^{\mathrm{a}}$ \\
\hline Vinf & - & - & - & - & $0.12 \pm 0.01^{b}$ & $0.15 \pm 0.00^{\mathrm{a}}$ \\
\hline M3G GVG & - & - & - & - & $0.13 \pm 0.01^{\mathrm{b}}$ & $0.21 \pm 0.18^{\mathrm{a}}$ \\
\hline M3Gcm Vph & - & - & - & - & $0.09 \pm 0.01^{\mathrm{b}}$ & $0.21 \pm 0.18^{\mathrm{a}}$ \\
\hline Total & $29.77 \pm 1.67^{b}$ & $27.67 \pm 1.67^{\mathrm{b}}$ & $22.37 \pm 2.52^{c}$ & $23.82 \pm 1.90^{c}$ & $36.40 \pm 1.13^{\mathrm{a}}$ & $12.38 \pm 1.42^{\mathrm{d}}$ \\
\hline
\end{tabular}

Results represent the mean \pm SD for three replicates. Means in the same row with the same letter are not significantly different $(\mathrm{p}<0.05$ )

other authors (Rapp and Mandery, 1986) showed that concentrations less than $300 \mathrm{mg} / \mathrm{L}$ for $S$. pombe strains could improve the general complexity of the wine. However, this was not perceived during a sensory analysis. The formation of 2-phenylethanol is connected with floral aromas and is considered positive, and it was over the threshold limit of $7.5 \mathrm{mg} / \mathrm{L}$ in every case (Lambrechts and Pretorius, 2000) with higher values in S. cerevisiae 7VA fermentations with final values as high as $78 \mathrm{mg} / \mathrm{L}$. Other authors have reported greater production of this compound by other yeast species of as high as $180 \mathrm{mg} / \mathrm{L}$ (Lambrechts and Pretorius, 2000; Comitini et al., 2011; Gobbi et al., 2013; Benito et al., in press). Diacetyl was over the threshold of $5 \mathrm{mg} / \mathrm{L}$ established as objectionable (Lambrechts and Pretorius, 2000) in a trial of a malolactic fermentation in which the final concentration was approximately $14 \mathrm{mg} / \mathrm{L}$. Isoamyl acetate was detected in every assay at concentrations of less than $14 \mathrm{mg} / \mathrm{L}$ but always higher than the threshold of $0.26 \mathrm{mg} / \mathrm{L}$ (Lambrechts and Pretorius, 2000), which could contribute a fruity aroma described as banana. Ethyl lactate production was moderate in all fermentations, except the S. cerevisiae 7VA fermentation followed by a malolactic fermentation. The acetoin concentration was normal according to other authors who reported values in wine from undetectable levels to $80 \mathrm{mg} / \mathrm{L}$ (Romano and Suzzi, 1996; Romano et al., 2003; Shinohara et al., 1979). Acetoin has no negative organoleptic effects at those levels. However, non-selected Schizosaccharomyces strains showed levels as high as $100 \mathrm{mg} / \mathrm{L}$. Concentrations higher than $150 \mathrm{mg} / \mathrm{L}$ (Gonzalez et al., 2001) in wine can produce an unpleasant buttery flavor.

\subsection{Anthocyanins}

Table 3 shows the values for anthocyanins in the different fermentations. Vitisine A was detected in similar concentrations in all of the fermentations except for the one with a subsequent MLF. The lower concentration was detected in the S. cerevisiae assay with a MLF, probably because of the much lower pyruvic acid concentration (Table 1). Vitisine B was not detected for fermentations in which a subsequent MLF occurred. The Sc. pombe experiments had significantly higher values than the S. cerevisiae experiments. The formation of highly stable pigments such as Vitisines is connected with improved chromatic characteristics of the wine, especially during a long aging process (Morata et al., 2003) when stable pigment forms become more important than unstable forms. On the other hand, M3G was higher value with S. cerevisiae and decreased significantly up to $12 \mathrm{mg} / \mathrm{L}$ after the MLF. A similar effect was observed for other anthocyanins. The experiments with the wild Sc. pombe strains had significantly higher values (approximately $1 \mathrm{mg} / \mathrm{L}$ for M3G) than the other Sc. pombe strains. A direct strong connection with the acetaldehyde concentration to explain the Vitisine A content cannot be made. The total anthocyanin concentration was significantly higher for S. cerevisiae without the MLF, but it dropped significantly after the MLF. The total anthocyanin content for the experiments with the wild Sc. pombe was significantly higher than for the other Sc. pombe strains; it was approximately $28 \mathrm{mg} / \mathrm{L}$ and $23 \mathrm{mg} / \mathrm{L}$, respectively. For S. cerevisiae fermentations, the total anthocyanin concentration was $36 \mathrm{mg} / \mathrm{L}$; however, after MLF, the final concentration was

Table 4

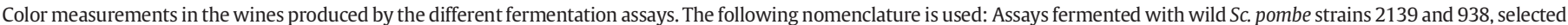
Sc. pombe strains V1 and 4.2, S. cerevisiae 7VA, and the letter $\mathrm{m}$ indicates assays in which malolactic fermentation with Oenococcus oeoni 217 occurred.

\begin{tabular}{|c|c|c|c|c|c|c|}
\hline Color measurements & 2139 & 938 & V1 & 4.2 & 7VA & 7VAm \\
\hline $420 \mathrm{~nm}$ & $0.09 \pm 0.01^{\mathrm{bc}}$ & $0.09 \pm 0,01^{\mathrm{bc}}$ & $0.11 \pm 0.00^{\mathrm{ab}}$ & $0.10 \pm 0.00^{\mathrm{ab}}$ & $0.08 \pm 0.00^{c}$ & $0.08 \pm 0.00^{c}$ \\
\hline $520 \mathrm{~nm}$ & $0.01 \pm 0.01^{\mathrm{bc}}$ & $0.09 \pm 0.01^{\mathrm{bc}}$ & $0.12 \pm 0.00^{\mathrm{a}}$ & $0.11 \pm 0.01^{\mathrm{ab}}$ & $0.10 \pm 0.00^{\mathrm{bc}}$ & $0.08 \pm 0.00^{\mathrm{c}}$ \\
\hline $620 \mathrm{~nm}$ & $0.00 \pm 00^{\mathrm{bc}}$ & $0.00 \pm 0.00^{\mathrm{bc}}$ & $0.01 \pm 0.00^{\mathrm{ab}}$ & $0.01 \pm 0.00^{\mathrm{ab}}$ & $0.00 \pm 0.00^{c}$ & $0.02 \pm 0.00^{\mathrm{a}}$ \\
\hline $\mathrm{dA} \%$ & $52.32 \pm 2.29^{\mathrm{b}}$ & $51.50 \pm 2.09^{\mathrm{bc}}$ & $48.01 \pm 0.76^{c}$ & $48.33 \pm 1.06^{\mathrm{bc}}$ & $56.68 \pm 0.51^{\mathrm{a}}$ & $38.80 \pm 2.28^{c}$ \\
\hline $\mathrm{CI}$ & $0.19 \pm 0.02^{\mathrm{bc}}$ & $0.19 \pm 0.02^{\mathrm{bc}}$ & $0.24 \pm 0.01^{\mathrm{a}}$ & $0.22 \pm 0.01^{\mathrm{ab}}$ & $0.18 \pm 0.01^{\mathrm{c}}$ & $0.18 \pm 0.01^{\mathrm{c}}$ \\
\hline Yellow: A420 (\%) & $47.01 \pm 0.97^{\mathrm{a}}$ & $47.50 \pm 0.51^{\mathrm{a}}$ & $46.71 \pm 0.67^{\mathrm{a}}$ & $46.91 \pm 0.40^{\mathrm{a}}$ & $46.81 \pm 0.46^{\mathrm{a}}$ & $46.36 \pm 0.56^{a}$ \\
\hline Red: A520 (\%) & $51.21 \pm 1.21^{\mathrm{b}}$ & $50.83 \pm 1.08^{\mathrm{bc}}$ & $49.03 \pm 0.37^{c}$ & $49.18 \pm 0.51^{\mathrm{bc}}$ & $53.58 \pm 0.29^{a}$ & $44.98 \pm 0.93^{c}$ \\
\hline Blue: A620 (\%) & $1.79 \pm 2.06^{\mathrm{bc}}$ & $1.67 \pm 1.59^{\mathrm{bc}}$ & $4.26 \pm 0.36^{\mathrm{b}}$ & $3.91 \pm 0.11^{\mathrm{b}}$ & $0.00 \pm 0.00^{c}$ & $8.67 \pm 1.10^{\mathrm{a}}$ \\
\hline Hue & $0.92 \pm 0.01^{\mathrm{bc}}$ & $0.93 \pm 0.01^{\mathrm{bc}}$ & $0.95 \pm 0.02^{\mathrm{b}}$ & $0.95 \pm 0.02^{\mathrm{b}}$ & $0.87 \pm 0.02^{\mathrm{b}}$ & $1.03 \pm 1.10^{\mathrm{a}}$ \\
\hline
\end{tabular}

Results represent the mean \pm SD for three replicates. Means in the same row with the same letter are not significantly different $(\mathrm{p}<0.05$ ). 
Table 5

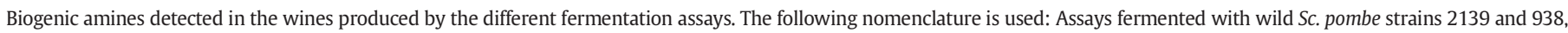
selected Sc. pombe strains V1 and 4.2, S. cerevisiae 7VA, and the letter $\mathrm{m}$ indicates assays in which malolactic fermentation with Oenococcus oeoni 217 occurred.

\begin{tabular}{|c|c|c|c|c|c|c|c|}
\hline Compounds (mg/L) & Must & 2139 & 938 & $\mathrm{~V} 1$ & 4.2 & 7VA & 7VAm \\
\hline Histamine & $0.42 \pm 0.01^{\mathrm{c}}$ & $0.30 \pm 0.01^{b}$ & $0.29 \pm 0.01^{b}$ & $0.30 \pm 0.01^{b}$ & $0.31 \pm 0.01^{\mathrm{b}}$ & $0.31 \pm 0.01^{\mathrm{b}}$ & $0.92 \pm 0.02^{\mathrm{a}}$ \\
\hline Tiramine & $0.26 \pm 0.01^{\mathrm{a}}$ & $0.19 \pm 0.01^{\mathrm{b}}$ & $0.20 \pm 0.01^{\mathrm{b}}$ & $0.20 \pm 0.01^{\mathrm{b}}$ & $0.19 \pm 0.01^{\mathrm{b}}$ & $0.19 \pm 0.01^{\mathrm{b}}$ & $0.25 \pm 0.01^{\mathrm{a}}$ \\
\hline Putrescine & $1.38 \pm 01^{\mathrm{a}}$ & $1.05 \pm 01^{\mathrm{c}}$ & $1.03 \pm 0.02^{\mathrm{c}}$ & $1.06 \pm 0.01^{\mathrm{c}}$ & $0.99 \pm 0.02^{\mathrm{d}}$ & $1.10 \pm 0.02^{\mathrm{b}}$ & $1.11 \pm 0.02^{b}$ \\
\hline Cadaverine & $0.64 \pm 0.01^{\mathrm{d}}$ & $0.40 \pm 0.01^{\mathrm{ab}}$ & $0.39 \pm 0.01^{b}$ & $0.41 \pm 0.01^{\mathrm{c}}$ & $0.36 \pm 0.01^{\mathrm{c}}$ & $0.42 \pm 0.01^{\mathrm{a}}$ & $0.43 \pm 0.01^{\mathrm{a}}$ \\
\hline
\end{tabular}

Results represent the mean \pm SD for three replicates. Means in the same row with the same letter are not significantly different ( $\mathrm{p}<0.05$ ).

reduced in $20 \mathrm{mg} / \mathrm{L}$. High anthocyanin levels are connected to a better color quality, improved mouthfeel and a better aging potential.

\subsection{Color measurements}

Table 4 shows the results for the color measurements of the different fermentations. No significant difference was found for the hue in the different fermentations other than one in which MLF occurred, which was slightly higher. The color intensity $(\mathrm{CI})$ was slightly higher for the assays of the selected Sc. pombe (greater for strain V1). The CI was not significantly different before and after the MLF for the S. cerevisiae experiments. The S. cerevisiae fermentations had a "redder" color, while the selected Sc. pombe had a more "bluish" color than the rest, probably indicating a younger wine.

\subsection{Biogenic amines}

The experiment in which a malolactic fermentation occurred showed the highest concentration of biogenic amines (Table 5). Schizosaccharomyces can restrict the activity of the indigenous lactic acid bacteria because it removes malic acid (another nutrient source). Indigenous or non-selected lactic acid bacteria can cause higher biogenic amine concentrations in wine (Alcaide-Hidalgo et al., 2007; Benito, 2015c), so Schizosaccharomyces can be used to prevent biogenic amine production. A special reference should be made for histamine. Fig. 6 shows the histamine levels for each fermentation. A value of $2 \mathrm{mg} / \mathrm{L}$ for histamine is considered the highest acceptable level in some countries due to food safety legislation (Lehtonen, 1996). The slight reported differences in cadaverine and putrescine could be explained by the different metabolic ability of the yeast to remove biogenic amines because these biogenic amines originate from the grapes. Other authors have reported a higher reduction of biogenic amines of up to $2.2 \mathrm{mg} / \mathrm{L}$ with alcoholic fermentation for the non-Saccharomyces species Hanseniaspora vineae (Medina et al., 2013). The urease enzymatic activity described for Schizosaccharomyces (Lubbers et al., 1996) could also reduce the level of ethyl carbamate precursors (Benito et al., 2014a, 2015c).

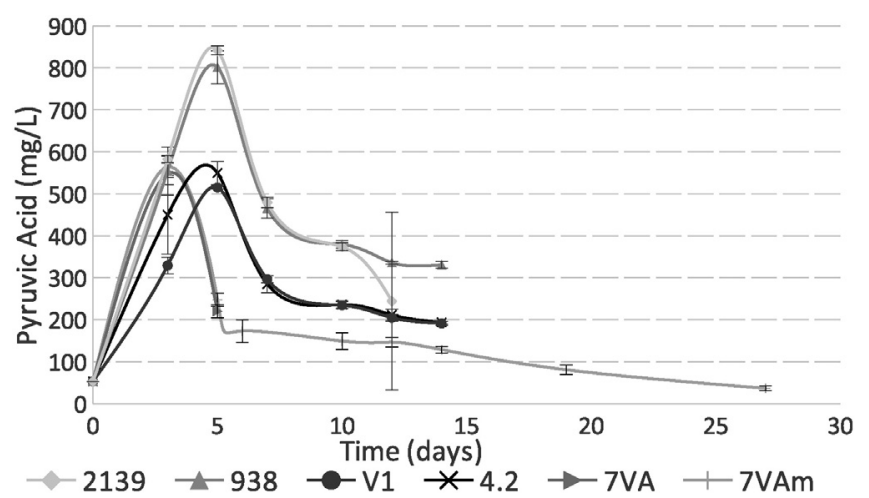

Fig. 6. Histamine concentrations in the final Tempranillo wines. The following nomenclature is used: Assays fermented with wild Sc. pombe strains 2139 and 938, selected Sc. pombe strains V1 and 4.2, S. cerevisiae 7VA, and the letter m indicates assays in which malolactic fermentation with Oenococcus oeoni 217 occurred.

\subsection{Sensory evaluation}

Fig. 7 shows the results obtained in the sensory evaluation. Fermentations involving Sc. pombe showed a perception of less general acidity (Fig. 7c), which is correlated with the final malic and lactic acid content (Table 1; Fig. 3). Differences in color intensity were observed (Fig. 7a). The fermentations with the selected Sc. pombe strains reached the highest values, which was in accordance with the previously recorded color intensity values (Table 4). On the other hand, experiments in which a malolactic fermentation occurred showed the lowest color intensity level and the highest value of color evolution, both of which are correlated with the low final anthocyanin values reported previously (Table 3). The acetic acid character and the volatile acidity perception were higher in the fermentations with the wild Sc. pombe strains 2139 and 938, which was related to the final acetic acid content (Table 1; Fig. 4a). The wild Sc. pombe strains 2139 and 938 and the S. cerevisiae strain 7VA showed a more fruity character, while the selected Sc. pombe strains V1 and 4.2 showed a spicier profile (Fig. 7b).

\section{Conclusion}

The primary conclusion of this study is that well-chosen Schizosaccharomyces pombe strains can contribute to wine quality and food safety. However, further research is necessary to select more appropriate Sc. pombe strains to produce a wine with the desired characteristics. Sc. pombe strains have great potential to produce less acidic, safer wines with a lower histamine content, a higher anthocyanin content and a higher color intensity.

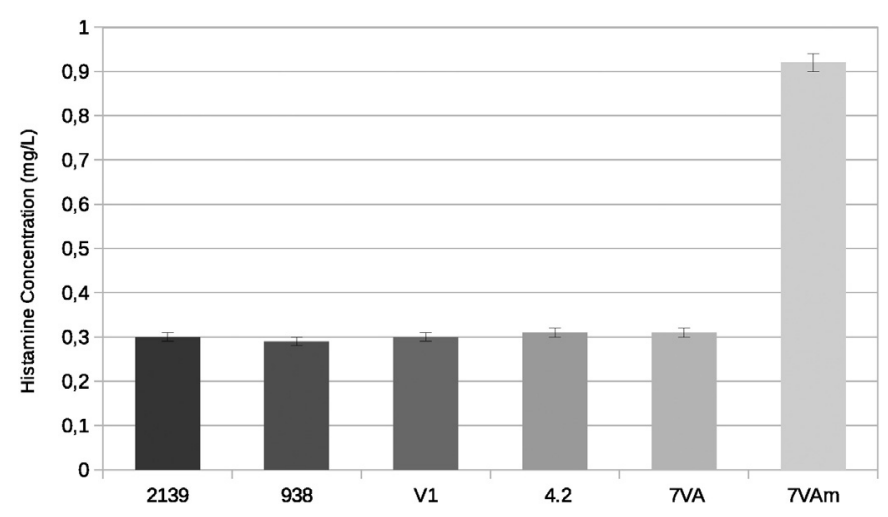

Fig. 7. a. Spider Graph of the color characteristics studied during the sensory analysis. The following nomenclature is used: Assays fermented with wild Sc. pombe strains 2139 and 938, selected Sc. pombe strains V1 and 4.2, S. cerevisiae 7VA, and the letter m indicates assays in which malolactic fermentation with Oenococcus oeoni 217 occurred. b. Spider Graph of the aroma characteristics studied during the sensory analysis. The following nomenclature is used: Assays fermented with wild Sc. pombe strains 2139 and 938, selected Sc. pombe strains V1 and 4.2, S. cerevisiae 7VA, and the letter $\mathrm{m}$ indicates assays in which malolactic fermentation with Oenococcus oeoni 217 occurred. c. Spider Graph of the retro-olfative characteristics studied during the sensory analysis. The following nomenclature is used: Assays fermented with wild Sc. pombe strains 2139 and 938, selected Sc. pombe strains V1 and 4.2, S. cerevisiae 7VA, and the letter m indicates assays in which malolactic fermentation with Oenococcus oeoni 217 occurred. 


\section{Acknowledgements}

This work was funded by the AGI2013-47706-R and by the Erasmus Mundus Scholarship program (Vinifera EuroMaster). The authors are very grateful for the help received from the accredited laboratory Estación Enológica de Haro and especially Montserrat Iñiguez and Elena Melendez for performing the biogenic amine analysis.

\section{References}

Alcaide-Hidalgo, J.M., Moreno-Arribas, M.V., Martín-Álvarez, P.J., Polo, M.C., 2007. Influence of malolactic fermentation, post fermentative treatments and ageing with lees on nitrogen compounds of red wines. Food Chem. 103, 572-581.

Belda, I., Navascués, E., Marquina, D., Santos, A., Calderón, F., Benito, S., 2015. Dynamic analysis of physiological properties of Torulaspora delbrueckii in wine fermentation and its incidence on wine quality. Appl. Microbiol. Biotechnol. 99 (4), 1911-1922. http://dx.doi.org/10.1007/s00253-014-6197-2.

Benito, S., 2015c. The use of Schizosaccharomyces yeasts in order to reduce the content of biogenic amines and ethyl carbamate in wines. J. Food Process. Technol. 6, 9-10.

Benito, S., Morata, A., Palomero, F., González, M.C., Suárez-Lepe, J.A., 2011. Formation of vinylphenolic pyranoanthocyanins by Saccharomyces cerevisiae and Pichia guillermondii in red wines produced following different fermentation strategies. Food Chem. 124, 15-23. http://dx.doi.org/10.1016/j.foodchem.2010.05.096.

Benito, S., Palomero, F., Morata, A., Calderón, F., Suárez-Lepe, J.A., 2012. New applications for Schizosaccharomyces pombe in the alcoholic fermentation of red wines. Int. J. Food Sci. Technol. 47, 2101-2108. http://dx.doi.org/10.1111/j.1365-2621.2012.03076.x.

Benito, S., Palomero, F., Morata, A., Calderón, F., Palmero, D., Suárez-Lepe, J.A., 2013. Physiological features of Schizosaccharomyces pombe of interest in making of white wines Eur. Food Res. Technol. 236, 29-36. http://dx.doi.org/10.1007/s00217-012-1836-2.

Benito, S., Palomero, F., Calderón, F., Palmero, D., Suarez-Lepe, J.A., 2014a. Schizosaccharomyces. In: Batt, C.A., Tortorello, M. (Eds.), Encyclopedia of Food Microbiology. Elsevier Ltd, Academic Press, pp. 365-370.

Benito, S., Palomero, F., Calderón, F., Palmero, D., Suárez-Lepe, J.A., 2014b. Selection of appropriate Schizosaccharomyces strains for winemaking. Food Microbiol. 42, 218-224. http://dx.doi.org/10.1016/j.fm.2014.03.014.

Benito, S., Palomero, F., Gálvez, L., Morata, A., Calderón, F., Palmero, D., Suárez-lepe, J.A 2014c. Quality and composition of red wine fermented with Schizosaccharomyces pombe as sole fermentative yeast, and in mixed and sequential fermentations with Saccharomyces cerevisiae. Food Technol. Biotechnol. 9862, 376-382.

Benito, S., Hofmann, T., Laier, M., Lochbühler, B.C. Schüttler, A., Ebert, K., Fritsch, S., Röcker, J., Rauhut, D., 2015a. Effect on quality and composition of Riesling wines fermented by sequential inoculation with non-Saccharomyces and Saccharomyces cerevisiae. Eur. Food Res. Technol. 241, 707-717.

Benito, Á., Calderón, F., Palomero, F., Benito, S., 2015b. Combine use of selected Schizosaccharomyces pombe and Lachancea thermotolerans yeast strains as an alternative to the traditional malolactic fermentation in red wine production. Molecules 20 9510-9523. http://dx.doi.org/10.3390/molecules20069510.

Benito, A., Calderón, F., Palomero, F., Benito, S., 2016. Quality and composition of airen wines fermented by sequential inoculation of Lachancea thermotolerans and Saccharomyces cerevisiae. Food Technol. Biotechnol. http://dx.doi.org/10.17113/ftb.54.02. 16.4220 (in press).

Carrau, F., Gaggero, C., Aguilar, P.S., 2015. Yeast diversity and native vigor for flavor phenotypes. Trends Biotechnol. 33, 148-154.

Clemente-Jimenez, J.M., Mingorance-Cazorla, L., Martínez-Rodríguez, S., Las Heras-Vázquez, F.J., Rodríguez-Vico, F., 2004. Molecular characterization and oenological properties of wine yeasts isolated during spontaneous fermentation of six varieties of grape must Food Microbiol. 21, 149-155. http://dx.doi.org/10.1016/S0740-0020(03)00063-7.

Comitini, F., Gobbi, M., Domizio, P., Romani, C., Lencioni, L., Mannazzu, I., Ciani, M., 2011. Selected non-Saccharomyces wine yeasts in controlled multistarter fermentations with Saccharomyces cerevisiae. Food Microbiol. 28, 873-882. http://dx.doi.org/10. 1016/j.fm.2010.12.001.

Contreras, A., Hidalgo, C., Henschke, P.A., Chambers, P.J., Curtin, C., Varela, C., 2014. Evaluation of non-Saccharomyces yeasts for the reduction of alcohol content in wine. Appl. Environ. Microbiol. 80, 1670-1678.

Contreras, A., Curtin, C., Varela, C., 2015. Yeast population dynamics reveal a potential 'collaboration' between Metschnikowia pulcherrima and Saccharomyces uvarum for the production of reduced alcohol wines during Shiraz fermentation. Appl. Microbiol Biotechnol. 99 (4), 1885-1895. http://dx.doi.org/10.1007/s00253-014-6193-6.

De Fatima, M., Centeno, F., Palacios, A., 2007. Desacidificación Biológica de Mosto a Través de la Inoculación de Levadura Schizosaccharomyces pombe Encapsulada como alternativa a la no producción de aminas biógenas. Bull. l'OIV 80, 277-281.

Deák, T., 2008. Handbook of Food Spoilage Yeasts, Second Edition. second ed. Boca Raton, USA, CRC Press: Taylor \& Francis Group.

Englezos, V., Rantsiou, K., Torchio, F., Rolle, L., Gerbi, V., Cocolin, L., 2015. Exploitation of the non-Saccharomyces yeast Starmerella bacillaris (synonym Candida zemplinina) in wine fermentation: physiological and molecular characterizations. Int. J. Food Microbiol. 199, 33-40. http://dx.doi.org/10.1016/j.ijfoodmicro.2015.01.009.

Esteve-Zarzoso, B., Manzanares, P., Ramón, D., Querol, A., 1998. The role of nonSaccharomyces yeasts in industrial winemaking. Int. Microbiol. 1, 143-148.

Fleet, G.H., 1999. Encyclopedia of Food Microbiology. Elsevier http://dx.doi.org/10.1006/ rwfm.1999.1415.

Fleet, G.H., 2008. Wine yeasts for the future. FEMS Yeast Res. 8, 979-995. http://dx.doi. org/10.1111/j.1567-1364.2008.00427.x.
Gao, C., Fleet, G.H., 1995. Degradation of malic and tartaric acids by high density cell suspensions of wine yeasts. Food Microbiol. 12, 65-71. http://dx.doi.org/10.1016/S07400020(95)80080-8.

Glories, Y., 1984a. La couleur des vins rouges. Mesure, origine et interprétation. Partie I. Connaissance de la Vigne et du Vin 18, 195-217.

Glories, Y., 1984b. La couleur des vins rouges. Mesure, origine et interprétation. Partie II. Connaissance de la Vigne et du Vin 18, 253-271.

Gobbi, M. Comitini, F, Domizio, P. Romani, C. Lencioni, L, Mannazzu, I, Ciani, M, 2013. Lachancea thermotolerans and Saccharomyces cerevisiae in simultaneous and sequential co-fermentation: a strategy to enhance acidity and improve the overall quality of wine. Food Microbiol. 33, 271-281. http://dx.doi.org/10.1016/j.fm.2012.10.004.

Gobbi, M., Comitini, F., Domizio, P., Romani, C., Lencioni, L., Mannazzu, I., et al., 2014. Fermentative aptitude of non-Saccharomyces wine yeast for reduction in the ethanol content in wine. Eur. Food Res. Technol. 239 (1), 41-48.

Gonzalez, E., Fernandez, M.R., Larroy, C., Pares, X., Biosca, J.A., 2001. Characterization and functional role of Saccharomyces cerevisiae 2,3-butanediol dehydrogenase. Chem. Biol. Interact. 130, 425-434.

Heier, A., Blaas, W., Dross, A., Wiittkowski, R., 2002. Anthocyanin analysis by HPLC/ESIMS. Am. J. Enol. Vitic. 53, 78-86.

Jolly, N.P., Augustyn, O.P.H., Pretorius, I.S., 2006. The role and use of non-Saccharomyces yeasts in wine production. S. Afr. J. Enol. Viticult. 27, 15-39.

Jolly, N.P., Varela, C., Pretorius, I.S., 2014. Not your ordinary yeast: non-Saccharomyces yeasts in wine production uncovered. FEMS Yeast Res. 14, 215-237. http://dx.doi. org/10.1111/1567-1364.12111

Kutyna, D.R., Varela, C., Henschke, P.A., Chambers, P.J., Stanley, G.A., 2010. Microbiological approaches to lowering ethanol concentration in wine. Trends Food Sci. Technol. 21, 293-302.

Lambrechts, M.G., Pretorius, I.S., 2000. Yeast and its importance to wine aroma: a review. S. Afr. J. Enol. Viticult. 21, 97-129.

Lehtonen, P., 1996. Determination of amines and amino acids in wine-a review. Am. J. Enol. Vitic. 47

Lubbers, M.W., Rodriguez, S.B., Honey, N.K., Thornton, R.J., 1996. Purification and characterization of urease from Schizosaccharomyces pombe. Can. J. Microbiol. 42, 132-140.

Magyar, I., Panyik, I., 1989. Biological deacidification of wine with Schizosaccharomyces pombe entrapped in Ca-alginate gel. Am. J. Enol. Vitic. 40.

Martini, A., Vaughan-Martini, A., 1998. Determination of ethanol production. In: Kurtzman, C.P., Fell, J.W. (Eds.), The Yeast, A Taxonomic Study. Elsevier Science Publishers, Amsterdam, p. 107

Medina, K., Boido, E., Fariña, L., Gioia, O., Gomez, M.E., Barquet, M., Gaggero, C., Dellacassa, E., Carrau, F., 2013. Increased flavour diversity of Chardonnay wines by spontaneous fermentation and co-fermentation with Hanseniaspora vineae. Food Chem. 141, 2513-2521. http://dx.doi.org/10.1016/j.foodchem.2013.04.056.

Morales, P., Rojas, V., Quirós, M., González, R., 2015. The impact of oxygen on the final alcohol content of wine fermented by a mixed starter culture. Appl. Microbiol. Biotechnol. 99 (9), 3993-4003. http://dx.doi.org/10.1007/s00253-014-6321-3.

Morata, A., Gómez-Cordovés, M.C., Colomo, B., Suárez, J.A., 2003. Pyruvic acid and acetaldehyde production by different strains of Saccharomyces cerevisiae: relationship with vitisin A and B formation in red wines. J. Agric. Food Chem. 51, 7402-7409. http://dx. doi.org/10.1021/jf0304167.

Morata, A., Gómez-Cordovés, M.C., Calderón, F., Suárez, J.A., 2006. Effects of pH, temperature and $\mathrm{SO} 2$ on the formation of pyranoanthocyanins during red wine fermentation with two species of Saccharomyces. Int. J. Food Microbiol. 106, 123-129. http://dx. doi.org/10.1016/j.ijfoodmicro.2005.05.019.

Morata, A., Calderon, F., Gonzalez, M.C., Gomez-Cordoves, M.C., Suarez, J.A., 2007. Formation of the high stable pyranoanthocyanins (vitisins A and B) in red wines by the addition of pyruvic acid and acetaldehyde. Food Chem. 100, 1144-1152.

Morata, A., Benito, S., Loira, I., Palomero, F., González, M.C., Suárez-Lepe, J.A., 2012. Formation of pyranoanthocyanins by Schizosaccharomyces pombe during the fermentation of red must. Int. J. Food Microbiol. 159, 47-53. http://dx.doi.org/10.1016/j. ijfoodmicro.2012.08.007.

Moreno-Arribas, M.V., Polo, M.C., 2008. Occurrence of lactic acid bacteria and biogenic amines in biologically aged wines. Food Microbiol. 25, 875-881.

OIV, 2013. International Code of Oenological Practices. Revised. ed. International Organization of Vine and Wine, Paris, France.

OIV, 2015. Compendium of international methods of wine and must analysis. International Organisation of Vine and Wine, Parise, France.

Palomero, F., Morata, A., Benito, S., Calderón, F., Suárez-Lepe, J.A., 2009. New genera of yeasts for over-lees aging of red wine. Food Chem. 112, 432-441. http://dx.doi.org/ 10.1016/j.foodchem.2008.05.098.

Palomero, F., Ntanos, K., Morata, A., Benito, S., Suárez-Lepe, J.A., 2011. Reduction of wine 4-ethylphenol concentration using lyophilised yeast as a bioadsorbent: influence on anthocyanin content and chromatic variables. Eur. Food Res. Technol. 232, 971-977. http://dx.doi.org/10.1007/s00217-011-1470-4.

Parapouli, M., Hatziloukas, E., Drainas, C., Perisynakis, A., 2010. The effect of Debina grapevine indigenous yeast strains of Metschnikowia and Saccharomyces on wine flavour. J. Ind. Microbiol. Biotechnol. 37, 85-93. http://dx.doi.org/10.1007/s10295-0090651-7.

Peinado, R.A., Mauricio, J.C., Medina, M., Moreno, J.J. 2004a. Effect of Schizosaccharomyces pombe on aromatic compounds in dry sherry wines containing high levels of gluconic acid. J. Agric. Food Chem. 52, 4529-4534. http://dx.doi.org/10.1021/jf049853r.

Peinado, R.A., Moreno, J.J., Maestre, O., Ortega, J.M., Medina, M., Mauricio, J.C., 2004b. Gluconic acid consumption in wines by Schizosaccharomyces pombe and its effect on the concentrations of major volatile compounds and polyols. J. Agric. Food Chem. 52, 493-497. http://dx.doi.org/10.1021/jf035030a.

Peinado, R.A., Moreno, J.J., Medina, M., Mauricio, J.C., 2005. Potential application of a glucose-transport-deficient mutant of Schizosaccharomyces pombe for removing 
gluconic acid from grape must. J. Agric. Food Chem. 53, 1017-1021. http://dx.doi.org/ 10.1021/jf048764b.

Peinado, R.A., Moreno, J.J., Maestre, O., Mauricio, J.C., 2007. Removing gluconic acid by using different treatments with a Schizosaccharomyces pombe mutant: Effect on fermentation byproducts. Food Chem. 104, 457-465. http://dx.doi.org/10.1016/j. foodchem.2006.11.070

Pretorius, I.S., 2000. Tailoring wine yeast for the new millennium: novel approaches to the ancient art of winemaking. Yeast 16, 675-729.

Rapp, A., Mandery, H., 1986. Wine aroma. Experentia 42, 873-884.

Rapp, A., Pretorius, P., Kugler, D., 1992. Off-Flavors in Foods and Beverages, Developments in Food Science, Developments in Food Science. Elsevier http://dx.doi.org/10.1016/ B978-0-444-88558-6.50025-8.

Romano, P., 2003. Function of yeast species and strains in wine flavour. Int. J. Food Microbiol. 86, 169-180. http://dx.doi.org/10.1016/S0168-1605(03)00290-3.

Romano, P., Suzzi, G., 1993. Higher alcohol and acetoin production by Zygosaccharomyces wine yeasts. J. Appl. Bacteriol. 75, 541-545. http://dx.doi.org/10.1111/j.1365-2672. 1993.tb01592.x.

Romano, P., Suzzi, G., 1996. Origin and production of acetoin during wine yeast fermentation. Appl. Environ. Microbiol. 62, 309-315.

Romano, P., Granchi, L., Caruso, M., Borra, G., Palla, G., Fiore, C., Ganucci, D., Caligiani, A., Brandolini, V., 2003. The species-specific ratios of 2,3-butanediol and acetoin isomers as a tool to evaluate wine yeast performance. Int. J. Food Microbiol. 86, 163-168.

Shimazu, Y., Mikio Uehara, M., Watanabe, M., 1985. Transformation of Citric Acid to Acetic Acid, Acetoin and Diacetyl by Wine Making Lactic Acid Bacteria. Agric. Biol. Chem. 49 (7), 2147-2157. http://dx.doi.org/10.1080/00021369.1985.10867041.

Shinohara, T., Shimazu, Y., Watanabe, M., 1979. Dosage de l'acétoïne et du lactate d'éthyle dans les vins par chromatographie en phase gazeuse, et étude de leur formation dans les vins. Agric. Biol. Chem. 43, 2569-2577.
Silva, S., Ramón-Portugal, F., Andrade, P., Abreu, S., Texeira, M.F., Strehaiano, P., 2003. Malic acid consumption by dry immobilized cells of Schizosaccharomyces pombe. Am. J. Enol. Vitic. 54.

Snow, P.G., Gallander, J.F., 1979. Deacidification of white table wines through partial fermentation with Schizosaccharomyces pombe. Am. J. Enol. Vitic. 30.

Suárez-Lepe, J.A., Leal, I., 2004. Oenological Microbiology: Fundamentals of Winemaking. Mundi-Prensa, Madrid.

Suárez-Lepe, J.A., Palomero, F., Benito, S., Calderón, F., Morata, A., 2012. Oenological versatility of Schizosaccharomyces spp. Eur. Food Res. Technol. 235, 375-383.

Taillandier, P., Gilis, M., Strehaiano, P., 1995. Deacidification by Schizosaccharomyces: interactions with Saccharomyces. J. Biotechnol. 40, 199-205. http://dx.doi.org/10. 1016/0168-1656(95)00046-S.

Terrade, N., Mira de Orduña, R., 2009. Determination of the essential nutrient requirements of wine-related bacteria from the genera Oenococcus and Lactobacillus. Int J. Food Microbiol. 133, 8-13. http://dx.doi.org/10.1016/j.ijfoodmicro.2009.03.020.

Thornton, R.J., Rodriguez, S.B., 1996. Deacidification of red and white wines by a mutant of Schizosaccharomyces malidevorans under commercial winemaking conditions. Food Microbiol. 13, 475-482. http://dx.doi.org/10.1006/fmic.1996.0054.

Uthurry, C.a., Varela, F., Colomo, B., Suárez Lepe, J.A., Lombardero, J., García Del Hierro, J.R. 2004. Ethyl carbamate concentrations of typical Spanish red wines. Food Chem. 88, 329-336. http://dx.doi.org/10.1016/j.foodchem.2004.01.063.

Uthurry, C.a., Suárez Lepe, J.A., Lombardero, J., García Del Hierro, J.R., 2006. Ethyl carbamate production by selected yeasts and lactic acid bacteria in red wine. Food Chem. 94, 262-270. http://dx.doi.org/10.1016/j.foodchem.2004.11.017.

Zironi, R., Romano, P., Suzzi, G., Battistutta, F., Comi, G., 1993. Volatile metabolites produced in wine by mixed and sequential cultures of Hanseniaspora guilliermondii or Kloeckera apiculata and Saccharomyces cerevisiae. Biotechnol. Lett. 15, 235-238. http://dx.doi.org/10.1007/BF00128311. 